\title{
Cost-effectiveness of dobutamine stress cardiac magnetic resonance imaging in stable coronary artery disease - a post-hoc analysis
}

\author{
Sebastian Kelle*, George Petrov, Sarah Kern, Eckart Fleck, Ernst Wellnhofer \\ From 16th Annual SCMR Scientific Sessions \\ San Francisco, CA, USA. 31 January - 3 February 2013
}

\section{Background}

Dobutamine stress cardiac magnetic resonance imaging (DCMR) was not an established test for coronary ischemia in 2003/2004. Meanwhile, long-term outcome has demonstrated a strong prognostic value of negative DCMR testing (Kelle et al. JACC CVI 2011). However, only limited data are as yet available about reimbursement for and costeffectiveness of DCMR in patients with stable coronary artery disease (CAD).

\section{Methods}

An electronic patient information system (PIS) archive allowed the selection of a matched control group of patients undergoing cardiac catheterization (CA) without prior DCMR. Our institution takes part in the German Diagnose Related Groups (DRG) reimbursement scheme and has transmitted micro cost calculations for all in-hospital stays of patients to the InEK database since 2003. The study cohort of this "natural experiment" 2003-2004 comprises 706 patients with suspected coronary artery disease (284 female, mean age $60 \pm 10$ ). A group of patients with DCMR guided treatment strategy (DCMR) $(\mathrm{N}=264$; $C A: \mathrm{N}=65$; no $\mathrm{CA}: \mathrm{N}=199)$ was matched to a control group with $C A$ indicated by standard evaluation (SECA) $(\mathrm{N}=442)$.

\section{Results}

Framingham risk score did not differ significantly between groups (7.7 \pm 2.8 vs. $8.1 \pm 3.2)$. Outcome was better in DCMR than in SECA. This trend was borderline significant in the above sample. An evaluation in a larger sample (N=924; 270 SCMR; 654 SECA) comprising additional patients from this period without cost data demonstrated a significantly $(\mathrm{P}<0.006$ log-rank test) superior outcome in DCMR that persisted even after adjustment for cardiovascular risk and revascularization. Median incremental costs related to hospital stays were $12.713 € \pm 43.664 €$ (median $4864 €$ ) in the SECA and 4104 $€ \pm 4454 €$ (median 3387 $€)$ in the DCMR group. Differences were located on the ward, intensive care unit and operation room but not in the cath-lab. All types of costs particularly human resource costs were elevated in the SECA group. Incremental costeffectiveness ratio was calculated as $822 €$ per survival. Sensitivity analysis demonstrated that at least $750 € /$ per patient are saved by DCMR. Death, PCI, CABG, and hospital admissions were $6 \%, 1 \%, 1 \%$, and $35 \%$ in the DCMR and $11 \%, 34 \%, 20 \%$, and $97 \%$ in the SECA group over 8 years.

\section{Conclusions}

DCMR is cost-effective in competition with SECA even if a reimbursement of $750 €$ for each DCMR examination is calculated. This natural experiment allows the simulation of detailed realistic cost-effectiveness scenarios for health technology assessment of DCMR.

\section{Funding}

none.

Published: 30 January 2013

doi:10.1186/1532-429X-15-S1-08

Cite this article as: Kelle et al: Cost-effectiveness of dobutamine stress

cardiac magnetic resonance imaging in stable coronary artery disease -

a post-hoc analysis. Journal of Cardiovascular Magnetic Resonance 201315

(Suppl 1):08. 